\title{
Selection of sorghum for drought tolerance in a semiarid environment
}

\author{
P.S.C. Batista ${ }^{1}$, A.J. Carvalho ${ }^{1}$, A.F. Portugal ${ }^{2}$, E.A. Bastos ${ }^{3}$, \\ M.J. Cardoso ${ }^{3}$, L.G. Torres ${ }^{4}$, M.P. Mingote Júlio ${ }^{4}$ and C.B. de Menezes ${ }^{2}$ \\ ${ }^{1}$ Universidade Estadual de Montes Claros - Campus Janaúba, Janaúba, MG, \\ Brasil. \\ ${ }^{2}$ Embrapa Milho e Sorgo, Sete Lagoas, MG, Brasil. \\ ${ }^{3}$ Embrapa Meio-Norte, Teresina, PI, Brasil. \\ ${ }^{4}$ Universidade Federal de São João del-Rei - Campus Sete Lagoas, Sete \\ Lagoas, MG, Brasil. \\ Corresponding author: C.B. de Menezes \\ E-mail: cicero.menezes@embrapa.br \\ Genet. Mol. Res. 18 (1): gmr18194 \\ Received October 30, 2018 \\ Accepted December 20, 2018 \\ Published January 08, 2019 \\ DOI http://dx.doi.org/10.4238/gmr18194
}

\begin{abstract}
Drought stress is a serious obstacle for crop production, especially in arid and semi-arid areas of the world. Sorghum is a useful crop to grow in areas with erratic, poorly distributed or inadequate rainfall. To help determine the best alternatives, we evaluated 30 sorghum cultivars with and without water stress in the post-flowering plant stage. The work was carried out at the Experimental Station of Gorutuba, in Nova Porteirinha, MG, Brazil, during 2013 and 2014 seasons. The experimental design was a randomized complete block, with three replications and two water regimes. The traits evaluated were grain yield, number of days to flowering, plant height and 1,000 grain mass. Water restriction reduced the grain yield by $68.9 \%$ in $2013,31.2 \%$ in 2014 and $50.1 \%$ in the average of the two years. The genotypes with best grain yield stability were B.Tx635, SC 720 and BR012RxSC566. Water stress significantly reduced plant height and grain mass.
\end{abstract}

Key words: Sorghum bicolor; abiotic stress; drought tolerance; plant breeding 


\section{INTRODUCTION}

Sorghum (Sorghum bicolor) is an important crop for food and feed in several regions of the globe, being the fifth most important cereal in the world. It presents good adaptation for growing in environments with a water deficit, because of its dense and deep root system, ability to reduce transpiration through leaf rolling and stomatal closure, and reduced metabolic processes under drought stress (Blum, 2004; Reddy et al., 2009). Consequently, sorghum has great potential for cultivation in regions and seasons subjected to water stress, for instance as a succession crop (soybean-sorghum) in Brazil's Cerrado biome, also called an off-season crop.

Worldwide, drought is perhaps the most significant abiotic stress limiting crop productivity. Water deficit is one of the main causes of damage in metabolic and physiological processes of plants, leading to reductions in productivity (Taiz et al., 2017). Plant breeding mitigates the effects of drought by creating cultivars adapted to new climatic conditions, and resistant to evolving pests and diseases. The exploitation of drought tolerant crops, such as sorghum, reduce the impact of climate changes.

Despite being among the most drought tolerant cereals, the sorghum plant can suffer significant damage during its development, under strong water stress (Reddy et al., 2011; Menezes et al., 2015). Sorghum damage caused by drought stress is greater during reproductive stages than during the vegetative stage.

The area planted to grain sorghum in Brazil has not increased in the last decade. The main production areas are in Center-West region, in the states of Goiás and Mato Grosso, and in the Southeast region in the state of Minas Gerais. Sorghum yields in this country have failed to increase or have even declined because production has been pushed to marginal areas, poorer soils and late season. After harvesting soybeans, farmers sow corn in late January and early February. After that, they finish planting sorghum in the rest of the area, when the risk of water stress for corn is high. In addition, they usually plant sorghum without any fertilizers.

Rainfall during the months of April to July is erratic or poorly distributed. The rains often have a normal start but terminate prematurely, thereby exposing the crop to postflowering water stress. Other times, the season may start normally, but stop temporally for about two to three weeks, thereby exposing the plant to early season stress referred to as pre-flowering water stress.

Sorghum breeding must consider the unpredictability of the environment during the off-season, selecting hybrids that are tolerant to drought and efficient in nutrient uptake. Also, the genotypes x environments and genotype $\mathrm{x}$ year interactions play an important role in the phenotypic expression of the drought tolerance (Menezes et al., 2015; Batista et al., 2017). Therefore, for efficient selection for rought tolerance it is essential to evaluate genotypes in different years and locations. We evaluated the grain yield of 30 sorghum cultivars grown under two post-flowering water regimes, in order to select the more tolerant ones to use as parental lines in hybrids and for population development.

\section{MATERIAL AND METHODS}

Trials were carried out at the Experimental Station of Embrapa Maize and Sorghum, in Nova Porteirinha - MG, in the 2013 and 2014 seasons. Nova Porteirinha is in 
the mesoregion of the North of Minas Gerais, considered as a semi-arid area. The geographical coordinates are $15^{\circ} 48^{\prime} \mathrm{S}$ latitude and $43^{\circ} 18^{\prime} \mathrm{W}$ longitude. The climate, according to Köppen, is Aw (tropical with dry winter). The soil of the experimental area is a medium-textured Red-Yellow Latosol.

The climate is semi-arid, being a typical region for drought tolerance tests, because its rainfall is from November to March, having a well-defined dry season between May and October, which facilitates water control during experiments. The maximum and minimum temperature and the rainfall during the trials are presented in Figure 1.

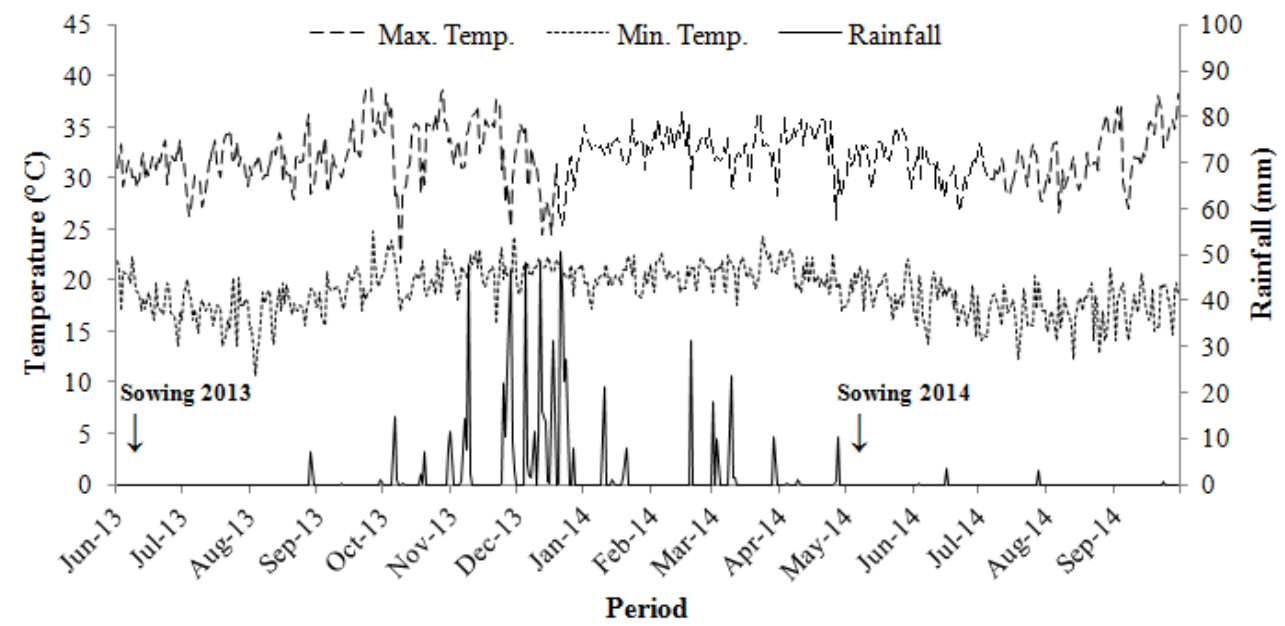

Figure 1. Rainfall (mm), maximum and minimum temperatures $\left({ }^{\circ} \mathrm{C}\right)$, during the trial periods in 2013 and 2014 in Nova Porteirinha, MG. (Source: INMET, 2017).

Thirty sorghum genotypes were subjected to two moisture regimes. In treatment-1, the cultivars were well-watered throughout the growing period to give full potential of the genotypes under non-stressed conditions. In treatment-2, the cultivars received adequate watering from germination to boot stage (just before the flowering stage) after which no more watering was applied. Treatment-2 simulated the post-flowering (terminal) moisture stress situation. Each combination of year and watering regimes was considered one environment, totaling four environments.

Plots were watered using sprinklers spaced $12.0 \times 12.0 \mathrm{~m}$ apart, with of $250 \mathrm{kPa}$ operating pressure, $4.0 \times 2.6 \mathrm{~mm}$ nozzles, and a flow of $1.6 \mathrm{~m}^{3} \mathrm{~h}^{-1}$. The irrigation management was based on the crop's evapotranspiration. An experimental design of randomized complete blocks was used, with three replications and plots of four rows of $3 \mathrm{~m}$ in length and $0.5 \mathrm{~m}$ between rows. The two central rows of each plot were harvested. Sowing was carried out with excess seeds; after thinning at 30 days after sowing, the plant density was 180,000 plants $\mathrm{ha}^{-1}$.

Starter fertilizers were applied using $250 \mathrm{~kg} \mathrm{ha}^{-1}$ of 8-28-16 (NPK). Also, $72 \mathrm{~kg} \mathrm{ha}^{-1}$ of $\mathrm{N}$ was side-dressed, using urea as a nitrogen source, 30 days after planting. Weeds were managed with atrazine (2-chloro-4-ethylamine-6-isopropylamine-s-triazine) at $3.0 \mathrm{~kg} \mathrm{ha}^{-1}$. The crop management consisted of two hand howings and applications of insecticides for the control of armyworm. Soon after flowering, plants had the panicles protected with polyethylene bags to prevent bird damage. 
The following characteristics were measured: grain yield, days to flowering, plant height and mass of 1,000 grains. Yield was obtained by weighing the grain mass, corrected to $13 \%$ moisture, transforming the results to $\mathrm{kg} \mathrm{ha}^{-1}$. Days to flowering was estimated by counting the number of days between sowing and the moment when more than $50 \%$ of the plants in the plot achieved anthesis. The height of the plants was obtained by measuring the distance between the ground and the apex of the panicle at physiological grain maturity. The mass of 1,000 grains was obtained from two samples of grains taken randomly from each plot.

Data were subjected to the individual variance analysis, considering the effect of the hybrids as fixed and the other effects as random. The yields under the water regimes were compared using the Tukey test $(\mathrm{P}<0.05)$. These analyses were performed using Sisvar Software 5.3 (Ferreira, 2011). Means of each water condition were presented using boxplot figures, produced by using the R package (R Development Core Team, 2016). Since the ratio between the greatest and the smallest mean square of the individual analysis of variance for grain yield did not exceed 7:1, a joint analysis of the trials was performed (Banzatto and Kronka, 2006). After that, the grain yield data were submitted to adaptability and stability analysis using the GGE biplot method (Yan et al., 2000).

The GGE Biplot model used was:

$$
Y i j-\mu-\beta j=y 1 \varepsilon i 1 \rho j 1+y 2 \varepsilon i 2 \rho j 2+\varepsilon i j
$$

where $\mathrm{Yij}$ is the grain yield average of genotype in environment $\mathrm{j} ; \mu$ is the general mean of the observations; $\beta \mathrm{j}$ is the principal effect of the environments; $y 1$ and $y 2$ are the scores associated with the first (PC1) and the second principal component (PC2) respectively; zi1 and $\varepsilon i 2$ are the values of $\mathrm{PC} 1$ and $\mathrm{PC} 2$ of the genotype i respectively; $\rho \mathrm{j} 1$ and $\rho \mathrm{j} 2$ are the values of $\mathrm{PC} 1$ and $\mathrm{PC} 2$ for the environment $\mathrm{j}$ respectively; and eij is the error associated with the model of the $\mathrm{i}$-th genotype and $\mathrm{j}$-th environment (Yan et al., 2000). The GGE biplot analysis used the GGEGui package implemented in the R software ( Development Core Team, 2016).

\section{RESULTS}

The number of days to flowering in 2013 under stressed (WS13) and non-stressed conditions (NS13) varied from 60 to 83 and from 61 to 79 respectively. In 2014, the number of days for flowering varied from 49 to 70 under non-stressed (NS14) and from 53 to 63 under stressed conditions. The cultivars were earlier in 2014 than in 2013, but there were no significant differences between the two water conditions in the two years (Table 1; Figure 2a). The earliest cultivars were SC704, Hegari, SC1345, Ajabsido and P898012, and the latest cultivars were 9503062, BR012R (BR012RxSC549), CMSXS180R and BR012R(BR012RxCMSXS225)-2.

In 2013 under non-stressed conditions, the plant height varied from 83 to $166 \mathrm{~cm}$ and under stressed condition from 68 to $128 \mathrm{~cm}$. In 2014 under non-stressed conditions, plant height varied from 74 to $159 \mathrm{~cm}$ and under stressed conditions from 92 to $152 \mathrm{~cm}$. The plants were smaller under stressed conditions (Table 1; Figure 2b) and in 2013 it was smaller than in 2014. The shortest plant cultivars were SC1038, 9503062, SC704, BR012R (BR012RxSC566) and BR012R (BR012RxSC549), and the tallest plant cultivars were SC720, SC373, HEGARI, SC672 and SC971. 
Grain mass was strongly reduced by water restriction, and most genotypes showed a significant reduction under stressed conditions (Table 1; Figure 2c). In 2013, under non-stressed conditions, the mean was $21 \mathrm{~g}$ and under stressed conditions, it was reduced to $16 \mathrm{~g}$. In 2014, under non-stressed conditions, the mean was $25 \mathrm{~g}$, and under stressed conditions, it was reduced to $18 \mathrm{~g}$. On average, water restriction reduced the weight of a thousand grains by $23 \%$ in 2013 and $31 \%$ in 2014.

Table 1. Average grain yield $\left(\mathrm{kg} \mathrm{ha}^{-1}\right)$ of 30 sorghum genotypes grown under water stress (WS) and non-stressed (NS) conditions, during the years 2013 and 2014. Nova Porteirinha, MG, Brazil.

\begin{tabular}{|c|c|c|c|c|c|c|}
\hline Treatment & Genotypes & $\mathrm{NS13}^{/ 1}$ & WS13 & NS14 & WS14 & General Mean \\
\hline 1 & SC704 & 3747 & 1122 & 2765 & 2035 & 2417 \\
\hline 2 & SC1345 & 3433 & 1267 & 2808 & 3474 & 2745 \\
\hline 3 & SC720 & 5020 & 2500 & 4715 & 3877 & 4028 \\
\hline 4 & HEGARI & 5010 & 1111 & 3784 & 2979 & 3221 \\
\hline 5 & Ajabsido & 4998 & 1467 & 4167 & 2869 & 3375 \\
\hline 6 & SC373 & 3214 & 1656 & 3509 & 2707 & 2771 \\
\hline 7 & P898012 & 5504 & 1900 & 4348 & 4120 & 3968 \\
\hline 8 & $\mathrm{SC} 103$ & 3891 & 900 & 3734 & 2070 & 2649 \\
\hline 9 & SC502 & 4541 & 1100 & 2983 & 2045 & 2667 \\
\hline 10 & SC645 & 3613 & 1767 & 4617 & 3230 & 3307 \\
\hline 11 & B. $\mathrm{x} 2752$ & 5011 & 1178 & 4860 & 3565 & 3653 \\
\hline 12 & SC627 & 5721 & 1589 & 5052 & 2729 & 3773 \\
\hline 13 & SC672 & 4987 & 1567 & 4057 & 2045 & 3164 \\
\hline 14 & SC971 & 5495 & 2322 & 4439 & 4258 & 4129 \\
\hline 15 & SC414_12 & 4999 & 1150 & 6246 & 2416 & 3703 \\
\hline 16 & SC209 & 3852 & 483 & 2907 & 1559 & 2200 \\
\hline 17 & SC115 & 3852 & 1044 & 3226 & 2602 & 2681 \\
\hline 18 & SC1124 & 3143 & 1256 & 2658 & 2443 & 2375 \\
\hline 19 & B.AZ9504 & 4597 & 1600 & 5410 & 2074 & 3420 \\
\hline 20 & R.Tx436 & 3953 & 267 & 4218 & 1478 & 2479 \\
\hline 21 & R.Tx2903 & 4334 & 967 & 5494 & 2550 & 3336 \\
\hline 22 & SC1038 & 3449 & 556 & 3511 & 1755 & 2318 \\
\hline 23 & Lian Tang Ai & 5705 & 1489 & 4458 & 3386 & 3759 \\
\hline 24 & B.Tx635 & 4957 & 1567 & 4835 & 4498 & 3964 \\
\hline 25 & R.Tx432 & 4503 & 844 & 5679 & 3652 & 3670 \\
\hline 26 & BR012RxSC549 & 4464 & 1844 & 4992 & 3667 & 3742 \\
\hline 27 & BR012RxSC566 & 4919 & 2844 & 4868 & 4396 & 4257 \\
\hline 28 & BR012RxCMSXS225 & 5550 & 2400 & 4165 & 3447 & 3891 \\
\hline 29 & CMSXS180R & 4439 & 1244 & 3983 & 2734 & 3100 \\
\hline 30 & 9503062 & 4086 & 1000 & 5053 & 3033 & 3293 \\
\hline General mean & & 4500 & 1400 & 4251 & 2923 & 3269 \\
\hline
\end{tabular}

${ }^{\dagger}$ NS13: Non-stressed in 2013 season; WS13: under water stress in the 2013 season; NS14: Non-stressed in the 2014 season; WS14: under water stress in the 2014 season.

The grain yield average considering the four environments was $3,269 \mathrm{~kg} \mathrm{ha}^{-1}$. The non-stressed trial in 2013 (NS13) presented the highest yield (4,500 $\mathrm{kg} \mathrm{ha}^{-1}$ ), and the trial under water stress in 2013 (WS13) the lowest yield $\left(1,400 \mathrm{~kg} \mathrm{ha}^{-1}\right)$. In 2014, under non-stress conditions, the grain yield was $4,251 \mathrm{~kg} \mathrm{ha}^{-1}$, and the trial under water stress yielded $2,923 \mathrm{~kg} \mathrm{ha}^{-1}$. Water stress reduced the grain yield by $68.9 \%$ in 2013 , $31.2 \%$ in 2014 and $50.1 \%$ in the average of the two years (Table 1; Figure 2d). Under non-stressed conditions, grain yield did not differ from one year to another, but under stressed conditions in 2013 it was lower than in 2014. The cultivars with highest yield under non-stressed condition were B.AZ9504, Lian Tang Ai, R.Tx432, SC627 and SC414_12, and the cultivars with highest yield under stressed conditions were BR012R (BR012RxSC549), BR012RxCMSXS225, P898012, B.Tx635, SC720, SC971 and BR012R (BR012RxSC566). 

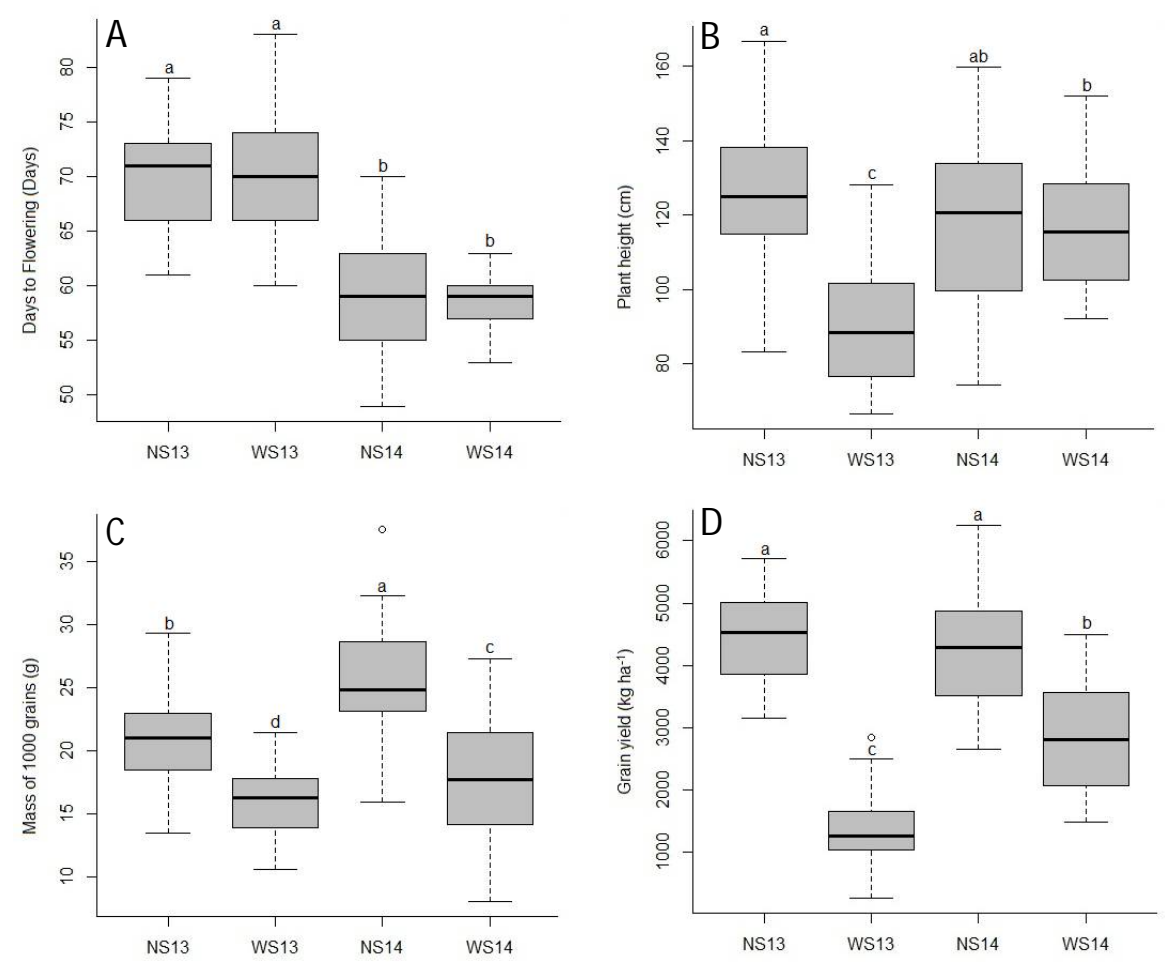

Figure 2. Boxplot analysis for number of days to flowering (a), plant height (b), mass of 1000 grains (c) and grain yield (d) of 30 sorghum genotypes evaluated under water stress in 2013 (WS13); under non-stressed conditions in 2013 (NS13); under water stress in 2014 (WS14); under non-stressed conditions in 2014 (NS14).

${ }^{\ddagger}$ Means followed by the same letter, for the same characteristic, do not differ from each other by the Tukey test $(\mathrm{p}<$ $0.05)$.

The performance and stability of the cultivars were visualized graphically through a GGE biplot (Figure 3). In the GGE biplot method, the principal components (PC1 and PC2) derived from the decomposition of the singular values of the effects of genotypes and the GxE interaction were presented. PC1 indicates cultivar adaptability and PC2 indicates phenotypic stability (Yan et al., 2000). The main components, PC1 and PC2, explained 60.58 and $23.96 \%$ of the total data variation, respectively (Figure3). These values confer reliability in the explanation of the total variation of the yield performance of the genotypes, plus the interaction with the environment $(G+G x E)$.

In the biplot "sectors and mega-environments" (Figure 3a), there is a polygon that connects the genotypes that are farthest from the center of the biplot. Based on the lines that come from the origin of the biplot, the polygon is divided into six sectors. Each sector that has at least one environment forms a mega-environment. Thus, two mega-environments were formed, the first by environments WS13, WS14 and NS13 and the second formed by the environment WS14. 

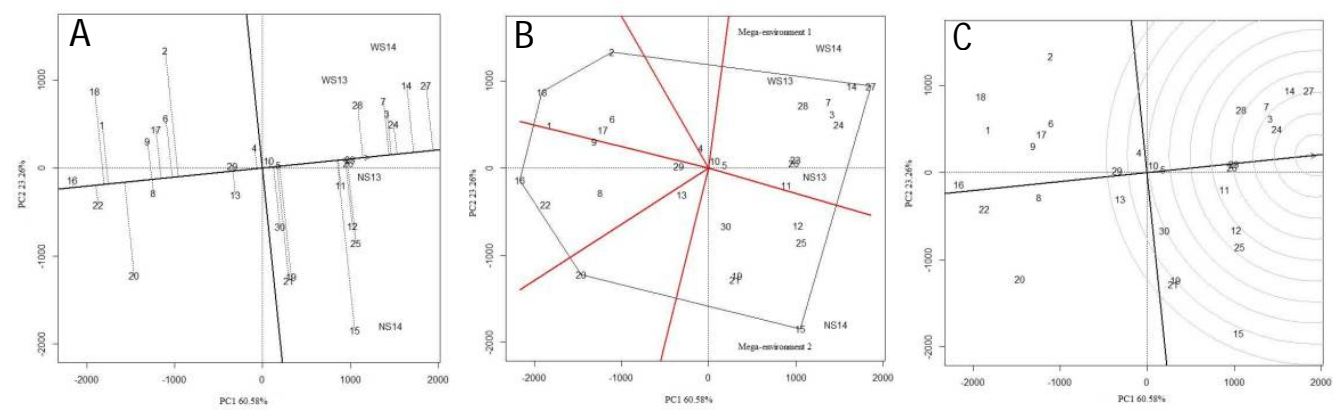

Figure 3.Sectors and mega-environments (a), average versus stability (b) and classification of genotypes (c), obtained by the GGE biplot model for grain yield of 30 sorghum cultivars evaluated under water stress in 2013 (WS13); under non-stressed condition in 2013 (NS13); under water stress in 2014 (WS14); under non-stressed conditions in 2014 (NS14).

According to Yan and Tinker (2006), genotypes plotted on the mega-environment are the most adapted to that environment and genotypes located at the vertices of each mega-environment feature the best performance. Consequently, cultivar BR012RxSC566 (27) showed the best performance considering the average of the three environments WS13, WS14 and NS13. Cultivars SC720 (3), Ajabsido (5), P898012 (7), SC645 (10), B.Tx2752 (11), SC971 (14), Lian Tang Ai (23), b. Tx635 (24), BR012RxSC549 (26) \& BR012RxCMSXS225 (28) also showed good performance for these environments. These genotypes had a higher grain yield in water-stress environments (WS13, WS14 and NS13) and therefore were the most adapted to these conditions.

In the NS14 environment, the best cultivar was SC414_12 (15). The genotypes SC627 (12), B.AZ9504 (19), R.Tx2903 (21), R.Tx432 (25) and 9503062 (30) were also well adapted to this environment. Genotypes belonging to sectors without the megaenvironment formation did not present high grain yield in any environment.

The biplot "Average vs. Stability" (Figure 3b) presents two axes, with the genotypes ranked in the most horizontal axis. This axis has an arrow pointing to the direction of higher grain yield. The farther right to the arrow that the cultivar is plotted, the higher its grain yield. On the other hand, the more to the left of the arrow, the lower is the grain yield (Yan, 2011). Thus, cultivars BR012RxSC566 (27), SC971 (14), B.Tx635 (24) SC720 (3), P898012 (7), BR012RxCMSXS225 (28), Lian Tang Ai (23) and BR012RxSC549 were the most productive in the average of all environments (Figure $3 \mathrm{~b}$ ). The vertical axis passing through the biplot origin separates cultivars with below-average yield from those with above-average yield. For instance, cultivar Hegari (4) is the first with yield below the average and cultivar SC645 (10) is the first with yield above the general average. The highest-yielding cultivar was BR012RxSC566 (27) and the lowest-yielding cultivar was SC209 (16).

Each genotype is linked to the horizontal axis (Figure 3b). The distance from this horizontal axis represents the stability of the genotypes. The greater the distance of the genotype in relation to the horizontal axis, the lower is its stability (Yan, 2011). Thus, the cultivars Lian Tang Ai (23), BR012RxSC549 (26), Ajabsido (5), SC645 (10), CMSXS180R (29) and SC209 (16) were the most stable genotypes, and SC414_12 (15), R.Tx2903 (21), B.AZ9504 (19) and SC1345 (2) were the most unstable genotypes. 
Genotypes with high stability and low yield are not desirable. High stability is a characteristic that only makes possible the indication of a genotype when it also presents outstanding performance. In this sense, the biplot "classification of genotypes" (Figure 3c) supports the selection, combining the adaptability and stability with grain yield of each genotype. This biplot presents concentric circles around the horizontal axis. The genotype closest to the center of the concentric circles is the most desirable one; that is it presents the best average performance (Yan, 2011) and is the most stable. Thus, genotype B.Tx635 (24) was the most desirable cultivar, because it presented high grain yield associated with high stability. Genotypes SC720 (3), BR012RxSC566 (27), SC971 (14), P898012 (7), BR012RxCMSXS225 (28), Lian Tang Ai (23) and BR012RxSC549 (26) had high grain yield, but were less desirable than B.Tx635 (24) due to lower stability.

\section{DISCUSSION}

The international demand for soybeans has led growers to plant all their area with soybean as the main summer crop, which has left corn to be planted as a second crop during the off-season. As a consequence, corn has pushed sorghum sowing to late planting, when the risk of water deficit is eminent. When sorghum is sown in February it is capable of good yields, but when sown after March the risk of strong water deficit is eminent, reducing yield. The development of a tolerant and adapted sorghum cultivar is essential for the late off-season in Brazil.

In Brazil, sorghum has been grown as a succession crop after soybean, during the autumn-winter season, when the risk of crop failure due to drought stress is well-known. The winter season is characterized by erratic, poorly distributed, and inadequate rainfall. The rains often have a normal start but terminate prematurely, thereby exposing the crop to post-flowering stress. The grain yield drop in environments with water stress involves various physiological processes in the plant. Water stress intensities are different from one place to another, and in the same place but in different years, showing the importance of other edaphoclimatic factors linked to water stress, and of experimental investigations in different years and locations. Climatic variations that occur from one year to another, and climatic factors, such as temperature, directly influence the intensity of water stress.

The trials in 2013 and 2014 were sowed in June and May respectively. When water was cut in stressed trials (late July and late June respectively), the temperatures in 2013 were much higher than in 2014, which explains, in part, the differences in the results (Figure 1). The stress under stressed condition in 2013 was greater than in 2014, resulting in a lower grain yield. Water stress reduced the grain yield by $68.9 \%$ in 2013, 31.2\% in 2014 and $50.1 \%$ in the average of the two years. Reduction caused by water stress were also observed by Menezes et al. (2015), who found reductions of 39\% in grain sorghum lines and by Batista et al. (2017), who found reductions of 35 and $65 \%$ in two years of evaluation in grain sorghum hybrids. Albuquerque et al. (2011) evaluated sorghum cultivars in a semiarid region, obtaining an average yield of $1,710 \mathrm{~kg} \mathrm{ha}^{-1}$ under low rainfall and $5,090 \mathrm{~kg} \mathrm{ha}^{-1}$ under good rainfall conditions. Sorghum is a cereal tolerant to drought, when compared to maize and wheat, but when it is exposed to intense water deficit, mainly during flowering, grain yield is significantly reduced.

The cultivars B.Tx635 (24), SC720 (3), BR012RxSC566 (27), SC971 (14), P898012 (7), BR012RxCMSXS225 (28), Lian Tang Ai (23), BR012xSC549 (26), 
B.Tx2752 (11), SC627 (12) and R.Tx432 (25) presented high yield and stability. These cultivars could be used as parental lines for hybrids production and/or in hybridization for population development.

The cultivars SC720 (Mutava, 2009), and P898012 (Leslie, 2008) are reported as drought tolerant, similar to what we found. Cultivars BR012RxSC566 (27), BR012RxCMSXS225 (28) and BR012xSC549 (26) are tolerant to aluminum (Carvalho Jr. et al., 2016), which means they have a good root system; this probably helps to mitigate the water deficit.

In addition to productivity, other characteristics are also important for selection of sorghum genotypes, under water restriction conditions, such as days to flowering, plant height and 1,000 grain mass. The number of days to flowering is a very important trait when selecting under post-flowering stress. Sorghum is sown as an off-season crop, at the end of the rainfall, and earlier maturity genotypes may escape from the water stress (Tardin et al., 2013). Besides that, the use of earlier genotypes allows anticipation of harvesting (Silva et al., 2009). Climatic conditions during the crop growth may directly influence the crop cycle.

There were no differences for days to flowering, under stressed and non-stressed conditions, in both years. This was expected, because water stress was applied after flowering. Comparing the two years, in 2014 the cultivars were earlier. The colder days (Figure 1) in the period prior to flowering, in 2013, may have increased the number of days to flowering. The second season has a very short period of rainfall, so one of the purposes of sorghum breeders is to select cultivars that are as early as possible, for drought escape, allowing the plant produce grain before the rain shortage. Considering the cultivars with highest yield and stability, SC720, P898012 and Lian Tang Ai were the earliest ones. These cultivars should be preferred when working for development of populations and hybrids for the late off-season in Brazil.

Other important trait for grain sorghum is plant height. According to Silva et al. (2009), genotypes that present shorter height, associated with greater stem resistance, had less susceptibility to lodging or plant breakage. For grain sorghum, plant height should be between 100 and $150 \mathrm{~cm}$ (Santos, 2005), since sorghum harvesting uses adaptations of machines normally used for corn or soybeans, which operate in this height range. Plants taller than $100 \mathrm{~cm}$ are better because height correlates with grain yield (Tardin et al., 2013). In our study, this correlation occurred in the WS13 environment, in which most of genotypes had a shorter height and lower grain yield. The best cultivars based on yield and stability had a plant height between 100 and $150 \mathrm{~cm}$, and can be used for grain sorghum hybrid development.

Decrease of grain mass in environments with water restriction can be explained by the reduction in the photosynthetic efficiency of the plants. Considering that the leaves are the centers of photoassimilate production, a reduction in photosynthesis reduces the exportation of these products to the other organs of the plants, especially the grains. This reduction in photosynthesis caused by water stress will result in lower carbohydrate production, which would result in a lower volume of dry matter in the grains (Magalhães and Durães, 2003). The grain mass was strongly reduced by water restriction, and most genotypes showed a significant reduction under stress conditions (Figure 2c). On average, water restriction reduced the weight of a thousand grains by 23\% in 2013 and $31 \%$ in 2014 . The main cause of reduced grain yield was grain size, which was severely affected by water 
stress. This trait should be explored when selecting sorghum for drought tolerance. The most stable cultivars presented heavier grains under stress conditions.

\section{CONCLUSIONS}

Water restriction significantly reduced grain yield during the two years of evaluation. The most stable and productive cultivars were B.Tx635, SC720, BR012RxSC566, SC971, P898012, BR012RxCMSXS225, Lian Tang Ai and BR012xSC549.The water restriction reduced plant height and grain mass.

\section{CONFLICT OF INTEREST}

The authors declare that they have no conflict of interest.

\section{ACKNOWLEDGMENTS}

Research supported by Embrapa Maize and Sorghum, FAPEMIG and CNPq.

\section{REFERENCES}

Albuquerque CJB, Von Pinho RG, Rodrigues JAS, Brant RS, et al. (2011). Espaçamento e densidade de semeadura para cultivares de sorgo granífero no semiárido. Bragantia 7: 278-285.

Batista PSC, Menezes CB, Carvalho AJ, Portugal AF et al. (2017). Performance of grain sorghum hybrids under drought stress using GGE biplot analyses. Genet.Mol. Res.16(3):gmr16039761.

Banzatto DA and Kronka SN (2006). Experimentação Agrícola.4 ed. Jaboticabal: FUNEP. 237 p.

Blum A (2004). Sorghum physiology. In: Nguyen HT, Blum A, editors. Physiology and Biotechnology Integration for Plant Breeding. New York: Marcel Dekker. 141-223.

Carvalho Jr G, Schaffert RE, Malosetti M, Viana JHM, et al. (2016). Back to acid soil fields: the citrate transporter SbMATE is a major asset for sustainable grain yield for sorghum cultivated on acid soils. G3 Gene. Genom. Genet.6: 475-484.

Instituto Nacional de Meteorologia - INMET (2017). Dados históricos. Available at: <http://www.inmet.gov.br/portal/index.php?r=bdmep/bdmep>. Accessed June 3, 2018.

Ferreira DF (2011). Sisvar: a computer statistic alanalysis system. Cienc. Agrotec.35: 1039-1042.

Landau ECandSans LMA (2012). Clima. In: Rodrigues, J. A. S. (Ed.). Cultivo do sorgo. 8. ed. Sete Lagoas: Embrapa Milho e Sorgo. (Sistema de produção, 2).

Leslie J (2008). Sorghum and Millets Diseases. Iowa State Press, Ames, Iowa, http://dx.doi.org/10.1002/9780470384923.

Magalhães PC and Durães FOM (2003). Ecofisilogia da produção de sorgo: Sete Lagoas: EMBRAPA. 4p. (Comunicado Técnico, 87).

Menezes CB, Saldanha DC, Santos CV, Andrade LC, et al. (2015). Evaluation of grain yield in sorghum hybrids under water stress. Genet. Mol. Res.14:12675-12683.

Pale S, Mason, SC and Galusha T (2003). Planting time for early-season pearl millet and grain sorghum in Nebraska. Agron. J.95: 1047-1053.

R Development Core Team (2016). $R$ : a language and environment for statistical computing. Vienna: R Foundation for Statistical Computing. Disponível em: 〈http://www.R-project.org>. Accessed: June 3, 2018.

Reddy BVS, Ramesh S, Reddy PS and Kumar AA (2009). Genetic enhancement for drought tolerance in sorghum. Plant Breed. Rev. 31: 189-222.

Reddy BVS, Kumar AA, Ramesh S and Reddy PS (2011).Sorghum genetic enhancement for climate change adaptation. In: Crop Adaptation to Climate Change 1st edn (Yadav SS, et. al., eds) Wiley-Blackwell, Oxford.

Silva AG, Barros AS, Silva LHCP, Moraes EB, et al. (2009). Avaliação de cultivares de sorgo granífero na safrinha no sudoeste do estado de Goiás. Pesqui. Agrope. Trop. 39:168-174.

Subudhi PK, Rosenow DT and Nguyen HT (2000). Quantitative trait loci for the stay green trait in sorghum (Sorghum bicolor L Moench): consistency across genetic backgrounds and environments. Theor. Appl. Genet.101: 733-741. 
Taiz L, Zeiger E, Moller IM and Murphy A (2017). Fisiologia e desenvolvimento vegetal.6 ${ }^{\mathbf{a}}$ ed. Porto Alegre: Artmed, $858 \mathrm{p}$.

Tardin FD, Almeida Filho JE, Oliveira CM, Leite CEP, et al. (2013). Avaliação agronômica de híbridos de sorgo granífero cultivados sob irrigação e estresse hídrico. Rev. Bras. Milho Sorgo, 12:102-117.

Yan W, Hunt LA, Sheng Q and Szlavnics Z (2000). Cultivar evaluation and mega-environment investigation based on the GGE Biplot. Crop Sci. 40: 597-605.

Yan W and Tinker A (2006). Biplot analysis of multi environment trial data: principles and applications. Can. J. Plant Sci.86, 3, 623-645.

Yan W (2011). GGE Biplot vs AMMI Graphs for Genotype-by-Environment Data Analysis. J. Indian Soc. Agric. Stat., $65,2,181-193$. 